\title{
EL APROVECHAMIENTO DE TÉRMINOS A FINES DE LA EDAD MEDIA CASTELLANA EN LAS COMUNIDADES DE VILLA Y TIERRA SERRANAS: PLASENCIA, BÉJAR, VALDECORNEJA, ARENAS, MOMBELTRÁN Y CANDELEDA
}

\section{SUMARIO}

I. El aprovechamiento en bienes comunales y concejiles: 1) Dominio de la Villa sobre la Tierra; 2) Cuotas, cotos, cercas y dominio señorial - II. Relaciones de Plasencia con su Tierra: 1) Formación de señoríos; 2) Recuperación de términos: 2.1) Pleitos - III. Conclusiones - IV. Bibliografía.

Mucho antes de que Alfonso VIII organizara la definitiva Reconquista y Repoblación de la Alta Extremadura, la Sierra de Béjar y la Sierra de Gredos a fines del siglo XII y principios del XIII, la vocación ganadera de toda esa amplia zona desde tiempo atrás había unido a sus habitantes e incluso había formado la Mancomunidad de pastos de Valdecorneja.

Con la creación de los Concejos mediante los Fueros concedidos por este Rey a Plasencia, Béjar y a los lugares de Valdecorneja (El Barco, Piedrahita, El Mirón y La Horcajada) y la consiguiente ordenación del territorio en Comunidades de Villa y Tierra (en tanto que el Sur de la Sierra de Gredos -Arenas, Mombeltrán y Candeleda- permaneció inscrito hasta fines del siglo XIV en el sexmo de las Ferrerías de Avila), se establecieron unas nuevas relaciones entre esas Comunidades para los pastos mediante privilegios reales, Ordenanzas y disposiciones concejiles, protegiéndose los intereses de la Comunidad frente a los de los «extraños» a ella, y se originaron dentro de cada Comunidad unas consustanciales a ella que repercutieron en el aprovechamiento comunal de sus términos, revistiendo especiales características en Plasencia por la instalación de señoríos en su Tierra.

Asimismo, el Derecho consuetudinario defendió el aprovechamiento comunal en la propiedad privada que coexistió junto a la propiedad concejil en la Comunidad por la venta o cesión de «propios» a particulares. Y es que la costumbre se basaba en que al fin y al cabo esas propiedades estaban dentro de la Comunidad. De esta forma, los dueños lo consintieron obedeciendo más la costumbre que por su voluntad; por eso en Plasencia no faltó su oposición a que los barbechos, eriazos y rastrojeras fueran pasto común o a que los vecinos entraran en sus tierras a cortar leña, cazar o pescar. 


\section{EL APROVECHAMIENTO COMUNAL EN BIENES COMUNALES CONCEJILES}

\section{1) Dominio de la Villa sobre la Tierra}

Todos los vecinos de la Comunidad de Villa y Tierra podían labrar, pastar, rozar, cortar, cazar y pescar en sus términos. Pero, en realidad, estos derechos no pudieron ejercerlos en todo el alfoz de la Comunidad, pues si en principio el Común de los vecinos debía ser el propietario y explotador de los términos, lo cierto es que el Concejo de la ciudad o villa se convirtió en el auténtico titular dominical de su alfoz, reservándose al Común sólo una parte de los bienes para su pleno disfrute: los bienes comunales o «comunes». Por eso el Concejo de la ciudad o villa pudo disponer del resto de los bienes para venderlos, cederlos, arrendarlos, etc., ya a una colectividad, ya a particulares, a fin de obtener ingresos para el arca municipal. Estos bienes eran los «propios» o también llamados en la documentación «concejiles», indicándonos así que pertenecían al Concejo y no al Común.

Junto a esos dos tipos de bienes, en la documentación placentina aparecen citados los «baldíos» del Arañuelo, unas veces como tierra de nadie y otras veces como tierras incultas, debido a que estaban lejos de la ciudad y a que se dedicaban preferentemente a pasto. Sin embargo, esos baldíos no son más que «propios» del Concejo de Plasencia. De ahí que a fines del siglo XV la ciudad intentara recuperar los usurpados para destinarlos al aprovechamiento agrícola, ganadero y forestal de los vecinos de Plasencia y de su Tierra.

Nos encontramos, por tanto, que en la Comunidad de Villa y Tierra la propiedad y el usufructo colectivo tienen cabida debido a la disociación entre el propietario y el titular del disfrute, y afecta a los vecinos de la villa o ciudad y a los de la Tierra, pues al resultar los comunes insuficientes para satisfacer las necesidades de los vecinos de la Comunidad, una parte de los «propios» se destinaron para «uso público".

Así pues, el aprovechamiento comunal se realizó también en bienes no comunales pero disfrutados por una colectividad, tal como se demuestra en la documentación, en donde se nombran a menudo tierras «concejiles y comunes» o «baldíos y comunes».

Ahora bien, esa colectividad no se trató siempre de toda la Comunidad de la Villa y Tierra, sino que en ocasiones fue «el común de los vecinos de la ciudad o villa» o «el común de los vecinos de la Tierra» o "el común de los vecinos de un Concejo de la Tierra» debido al vínculo patrimonial que ligaba a la Tierra con su ciudad o villa '. Porque, si en virtud de ese vínculo los Concejos de la Tierra pudieron reservarse terrenos en sus términos respectivos (a veces aparecen con el nombre de "heredad»), al igual que los vecinos de la ciudad o villa tenían tierras exclusivas para ellos, de la misma forma el Concejo de la ciudad o villa podía impedir el aprovechamiento comunal en «los concejiles» y «baldíos» a los de la Tierra, o bien beneficiaba sólo a algunos lugares de la Tierra. Sirvan de ejemplos del dominio de la ciudad o

1 Mangas Nabas (1981, p. 23). 
villa sobre la Tierra el que sólo cuatro lugares de Piedrahita tuvieron «propios» (eran Navarredonda, San Martín del Pimpollar, Hoyos del Espino y Hoyos del Collado), y que los lugares de Mombeltrán de ucumbres adentro" (Cuevas, San Esteban, Villarejo, Santa Cruz y Arroyo Castaño) no pudieron llevar sus ganados a ciertos prados ${ }^{2}$.

\section{2) Cuotas, cotos, cercas y dominio señorial}

Por el disfrute de los comunes no se pagaba nada. En cambio, los Concejos regularon la explotación de los concejiles y exigieron una cuota por su aprovechamiento. Así, Plasencia pidió un tributo sobre el ganado que pastó en el Campo del Arañuelo destinado a costear las obras de la muralla en $1450^{3}$, y el Concejo de Béjar se aseguró de percibir rentas de los montes de «propios» cobrando una cantidad por cada puerco que los vecinos metieran a pastar ${ }^{4}$. Además, Plasencia, Béjar y los lugares de Valdecorneja tomaron "el quinto" al ganado de fuera que pastaba en los "propios» y al de la propia Tierra que pastara en los concejiles sin cumplir ciertos requisitos.

En relación con la no gratuidad de los «propios» podemos considerar los censos colectivos que algunos lugares de Plasencia pagaron para poder disfrutar de términos concejiles. Esos lugares fueron Mirabel, Serradilla y Malpartida, que por estar asentados en dehesas adehesadas necesitaron esos concejiles como si fueran suyos propios. Y así, mediante el censo colectivo se explotaron esas tierras comunalmente, perteneciendo el usufructo al Común y al Concejo del lugar' . Bajo señorío el censo lo cobraría el Señor y no el Concejo de la ciudad. De ese modo, los vecinos de Mirabel, a cambio de 5.000 mrs. y 160 fanegas de trigo que pagarían al año, recibieron del Conde de Plasencia don Pedro de Estúñiga a mediados del siglo XV varias viñas y heredades y la tierra llamada "del Espinal y Navalmoral» 6.

Pero si el pago de una cuota o tributo podemos considerarlo como un impedimento al aprovechamiento comunal para los vecinos más pobres, sabemos que los acotamientos de tierras representaron el mayor obstáculo a ese aprovechamiento. $Y$ es que la presencia del ganado trashumante en todo este territorio sirvió para que los Concejos y propietarios de tierras obtuvieran rentas por el pasto y montanera y venta de hierba. Los Concejos acotaron los «propios» en determinadas épocas del año para arrendarlos al ganado «extraño», y los pastos de los «extremos» en la Tierra de Plasencia fueron aumentando en superficie en detrimento de las tierras dedicadas a pasto del propio ganado.

Un Memorial de agravios redactado por la Tierra placentina a fines del siglo XV o principios del XVI ' nos ilustra perfectamente esta situación. En él se denuncia a los

2 vs. Santos Canalejo (1986, p.400) y Tejero (1973, p. 130).

3 A. Duques de Frías, leg. 621 núm. 2. Ya en 1506 Tornavacas reclamará los maravedís dados para la muralla de la ciudad (leg. 621 núm. 3 ).

4 A. Mun. Béjar, Carp. 4 núm 4.

- AGS, Cám. Cast., Pueblos, leg. 13.

6 El Consejo de este lugar afirma que gracias a disponer de esas tierras el lugar se pobló (AGS, RGS., 1491 Agosto núm. 269).

1 AGS Cám. Cast. Pueblos leg. 15 
dueños de las dehesas de «estorbar" o «romper" el aprovechamiento comunal de leña, corcho y de los "veranaderos", es decir, de los pastos que quedaban al marcharse el ganado trashumante, cuando realmente eran «baldíos y comunes para uso público». Incluso los dueños encarcelaban a quienes se resistieran, ya que «son caballeros y los leñadores miserables personas», y por eso mismo tampoco «alcanzaban justicia» cuando los caballeros metían sus ganados en los concejiles de los lugares de la Tierra sin pagar la cuota exigida ${ }^{3}$. Además de todo esto, los dueños de las tierras unían tierras terrazgueras para formar dehesas privando a los labradores de tierras de cultivo «y de todo lo demás».

Los acotamientos de tierras, por tanto, significaron también los de la caza y pesca en ellas, y se debieron a Concejos, Señores y dueños de ellas. En Plasencia los caballeros dispusieron en el término de la ciudad de ciertos cotos de caza; luego, el Duque don Alvaro de Estúñiga poseería el suyo en esta ciudad y otro en Béjar. Por su parte, el señor de Valdecorneja, don García Álvarez de Toledo, acotaría la pesca y caza en su señorío. La incidencia de estos acotamientos fue tan grande para los vecinos, que don Fadrique Álvarez de Toledo desacotó la pesca y, en ciertos terrenos, la caza 9 y, cuando los regidores placentinos acotaron la pesca en la Isla, la ciudad aprovechó para solicitar que se desacotara y que la Isla fuera sitio de pasto común pese a que los regidores hubieran redactado la Ordenanza que prohibía meter allí ganado en primavera y en verano ${ }^{10}$.

Unos acotamientos que se desarrollaron al Sur de la Sierra fueron los denominados «adehesamientos», muy importantes en Plasencia, Arenas, Candeleda y, en menor medida, en Mombeltrán. Ya en el siglo XIV se afirmaba en Plasencia y en su Tierra que se habían formado a costa de los "concejiles» y «comunes». Las ganancias que depararon los "propios" adehesados fueron muy importantes ", relegándose como hemos visto las necesidades de pasto y labranza de los vecinos.

Además, bajo señorío ${ }^{12}$ ya no fue el Concejo quien dispuso de las tierras de su alfoz, sino el Señor. Buen ejemplo de ello es la afirmación de que el Duque de Béjar "podía hacer gracia de los comunes a quien quisiera», y por eso la villa se vio obligada a aceptar que los lugares de su Tierra gozaran de castaña y leña en la dehesa boyal de la Villa ${ }^{13}$. Igualmente, el Señor de Plasencia tomó tierras de los "propios» y comunes y potenció el adehesamiento del Campo del Arañuelo.

Otra manera de impedir el aprovechamiento comunal de pastos fue el de cercar tierras para huertos o viñas en terrenos dedicados tradicionalmente a otros cultivos que permitían después el pasto común. Es el caso del intento de los vecinos del barrio

\footnotetext{
- AGS, RGS, 1491, Marzo núm. 451.

9 vs. para los cotos y cercas en Valdecorneja, Santos Canalejo (1986,pp.368-369 y 407).

10 AGS, Cám. Cast. Pueblos leg. 15, y RGS, 1505 Agosto núm. 210 y 1506 Octubre.

11 En el Censo de 1528 se dice que la villa de Candeleda contaba con importantes rentas de upropiosn: 500.000 o 600.000 mrs. (AGS, Cont. Generales, leg. 768).

12 Los Estúniga poseyeron Béjar desde 1398, y Plasencia desde 1442 a 1488; los lugares de Valdecorneja pertenecerán a los Alvarez de Toledo desde 1369; y Arenas, Mombeltrán y Candeleda se convirtieron en villas en 1393 para ser señoríos del condestable Dávalos. (Sobre estos señoríos y su evolución, vs. Santos Canalejo, 1986, pp. 209-220).

13 AHN, Osuna, leg. 232 núm. 16 (1 y 3).
} 
de abajo de Aldeanueva del Camino, vasallos del Duque de Alba, de plantar viñas en los linares para que los vecinos del barrio de arriba, bajo la jurisdicción placentina, no pudieran pastar una vez recogido el lino ${ }^{14}$. La proliferación de cercados para huertos y viñas en la Vera y el Valle ocasionó que a principios del XV los vecinos de esos «sexmos" de la Tierra placentina fueran a labrar a los baldíos del Arañuelo, aún poco adehesado.

Diferente significado tuvo la cerca de los prados concejiles y privados en Valdecorneja, en donde el Señor y el Concejo regularon su uso comunal, al menos en determinadas épocas del año, señalando la cerca más la propiedad que un obstáculo al aprovechamiento comunal.

\section{RELACIONES DE PLASENCIA CON SU TIERRA}

\section{1) Formación de señorios}

En la Tierra placentina el proceso de adehesamiento fue paralelo a la formación y consolidación de señoríos en ella. Estos señoríos fueron creándose desde mediados del XIII, cuando caballeros atraídos por los privilegios reales o personajes que desempeñaban cargos palatinos compraron tierras o recibieron de los Reyes donaciones para que levantaran sus casas-fuerte a fin de que contribuyeran a la pacificación del territorio sometido a los robos de los golfines y, de este modo, favorecieran la

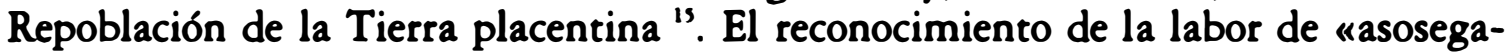
mienton de estos caballeros por la ciudad implicó que no pudiera evitar que su alfoz fuera mermado. De ahí que el Concejo placentino terminara por aceptar la compra de Jaraicejo que hizo Pedro Sánchez de la Cámara con la autorización de Sancho IV en 1288, si bien Pedro Sánchez debió renunciar a otros términos que según él le había dado el Rey ${ }^{16}$. La admisión de Plasencia de este señorío en su Tierra implicaba que los vecinos de aquel lugar participaran de los privilegios de su condición de vasallos y a la vez de los derechos de los del resto de los lugares de la Tierra placentina, pudiendo pastar, cazar y cortar en los términos de Plasencia según disposición de Sancho IV, y que se seguirían manteniendo después del pleito de 1338 entre la ciudad de Jaraicejo, aunque señalándose en contrapartida las obligaciones que debían cumplir los de Jaraicejo como los de la Tierra: acudir en apellido, defender los términos de Plasencia, contribuir para hacer puentes y en las compras para el acrecentamiento del alfoz placentino.

El resto de los lugares de señorío defendieron su aprovechamiento de los términos placentinos de la misma forma que Jaraicejo, resistiéndose muchas veces a cumplir con sus deberes como pertenecientes a la Tierra mientras que reinvindicaban sus derechos. Entonces la ciudad recurrió a Ordenanzas u otras disposiciones para restringir cuando no impedir cualquier posible derecho a aquellos señoríos,

14 AGS, RGS, 1501, Feb. y Nov.

is Estos señoríos fueron: el de Belvis, Almaraz, Monroy, Grimaldo, Torrejón, Jaraicejo, Valverde, Serrejón, Oliva, Jarandilla, Garganta la Olla. A ellos se sumará a fines del XV el de Mirabel (vs. Santos Canalejo, 1986, pp. 57-59 y 71-73).

16 v.s. acerca de Jaraicejo, Sánchez Loro (1983, pp. 40-68 y 205-209). 
siendo coincidente en ocasiones la actuación concejil con la de los Estúñiga, señores de Plasencia, aunque éstos a la vez contribuyeron y concedieron tierras de «propios» y comunes a varios señores, que, por su parte, no sólo ejercieron su jurisdicción sobre sus vasallos sino también sobre los campesinos de las tierras de pasto y labor que usurpaban, no próximas a veces a su señorío, teniendo así sus propiedades muy dispersas aunque por lo general en el Arañuelo. No es de extrañar que a fines del siglo XV muchos lugares de la Tierra vieran sus términos mermados e incluso desaparecidos y afirmen que estaban cercados de dehesas adehesadas ${ }^{17}$.

\section{2) Recuperación de términos}

\section{1) Pleitos}

La reducción de términos de aprovechamiento comunal debida tanto a la actitud de los propietarios de tierras, generalmente caballeros de la ciudad, como a la usurpación de concejiles y comunes que los Estúñiga y la propia oligarquía concejil de la ciudad permitieron, supuso que la recuperación de la integridad de su alfoz fuera una de las mayores preocupaciones del Concejo placentino, y también de su Tierra, que era la más perjudicada.

Para conseguir sus propósitos la ciudad aprovecharía los momentos de tranquilidad que siguieron a los períodos de gueras civiles en el Reino castellano, entablando pleitos con los señores y lugares de señorío primero en los años de 1376 y 1377, tras la guerra que subió al trono a los Trastámara, y luego a partir de 1488, cuando la ciudad volvió a pertenecer a la Corona, pues antes no pudo ser al ser los Estúñiga «deudos y ponentes de los señores», y fue al final de su vida cuando don Álvaro de Estúñiga había entregado a la ciudad los privilegios y escrituras que de ella guardaba en Béjar, pues le «remorcía la conciencia»". Sin embargo, precisamente porque los tiempos anteriores a los pleitos fueron belicosos, los reyes premiarían los servicios a sus partidarios y, si Enrique II confirmó los privilegios de Diego Gómez de Almaraz para avalar su señorío ${ }^{19}$, los Reyes Católicos permitieron que don Francisco de Estúñiga poseyera Mirabel ${ }^{20}$. Así pues, los señoríos no desaparecieron, pero Plasencia obtendrá algunos éxitos en sus demandas.

En 1376 y 1377 los pleitos sostenidos con el Señor de Belvis -Esteban Fernández del Bote-, con el Señor de Torrejón -Durán González-, con el señor de Almaraz -Diego Gómez de Almaraz- y con el Señor de Oropesa -Fernando Álvarez de Toledo-, demuestran el poderío en la Tierra placentina de estos señores que no se habían contentado con las tierras que los Reyes les habían asignado.

Para solucionar estos conflictos se adoptó la reciprocidad en el aprovechamiento de tierras, de modo que si los vecinos de Plasencia podían entrar en el término del señorío «para pastar, labrar, coger lande, barbechos, eriazos, agua...», los vecinos del

17 AGS, RGS 1494 Feb. núm. 450.

18 AGS, Cám. Cast. Pueblos. leg. 15

19 Sánchez Loro (1983, Pp. 261-313).

20 También le concedieron la alcabala de la dehesa de San Benito y 20.000 mrs. de la heredada y villa de Mirabel (AGS, CMC, 1.' Epoca, leg. 44). 
señorío podrían "usar» el término de la ciudad. Asimismo, se ordenó en las sentencias dadas que no se hicieran dehesas en los concejiles y que se devolviera lo usurpado al Concejo placentino para uso comunal. Aparece, pues, en estas sentencias la necesidad de tierras concejiles para el aprovechamiento comunal.

A pesar de todo, las apetencias señoriales por acrecentar sus posesiones continuaron y la oposición de los lugares de señorío a la regulación de "pastos, roza, labranza, pesca, caza, aguas y corte de madera» en el Arañuelo se reiteró durante todo el siglo $\mathrm{XV}^{21}$. Si a eso añadimos su progresivo adehesamiento, no es de extrañar que los lugares placentinos del Arañuelo fueran los que más se interesaron en los pleitos de fines de ese siglo.

Así pues, el deseo de la ciudad por recuperar sus términos no fue mayor que el manifestado por su Tierra, que prefirió dirigirse al juez de términos enviado por los Reyes Católicos independientemente de la ciudad, desconfiando de los caballeros y regidores placentinos que obstaculizaban la labor del juez que sentenciaba también contra ellos. No en balde la Tierra dirigió sus acusaciones a los regidores porque concedieron términos comunes y concejiles, favorecieron a determinados Concejos agraviando al resto de la Tierra y consintieron los abusos de los señores que eran sus amigos ${ }^{22}$.

De esta forma, mientras el primer juez de términos, el bachiller Francisco Francés, dictaba sus sentencias en 1492 contra algunos caballeros y contra el propio Concejo de la ciudad ${ }^{23}$, la conducta de la oligarquía concejil y la de los señores continuaba defendiendo sus intereses ligados a la ganadería y arrendamiento de pastos.

Consecuencia de todo ello fue que los pleitos se dilataran ocasionando grandes gastos, que en 1506 se encargara de esos pleitos un nuevo juez de términos -el bachiller Diego Fernández de Vergara ${ }^{24}$ y que entre tanto algunas aldeas de la Tierra tomaran los términos disputados antes de que finalizara el pleito ${ }^{25}$.

Para afrontar esos gastos la ciudad recurrió a los repartimientos debido a que con los "propios" no bastaba. Y del mismo modo que los regidores no aceptaron que la Tierra pleitara por su cuenta pues la Comunidad «era un cuerpo» ${ }^{26}$, toda ella debió contribuir en aquellos repartimientos, incluyéndose, por tanto, los propios lugares de señorío contra los que se pleiteaba. Al fin y al cabo, si los de señorío querían gozar de los comunes y concejiles con iguales derechos que los de los vecinos de Plasencia y sus lugares de la Tierra, también deberían aportar lo que les tocara para sufragar esos gastos como pertenecientes a la Comunidad. Los de señorío se quejaron reiteradamente e incluso consiguieron de los Reyes Católicos que fuera el Corregidor quien determinara la cuantía de los gastos y que cada lugar de señorío contribuyera cuando el pleito no fuera contra él ${ }^{27}$. Pero, por su parte, el Concejo

21 A. Duques de Frías, leg. 622, 624 y 628 núm. 2 y 3.

22 AGS, Exp. Hac. leg. 358; Cám. Cast. Pueblos, leg. 15; y RGS 1502 Abril y 1512 Feb.

23 AGS, RGS, 1492, Marzo núm. 285.

24 AGS, RGS, 1506 Feb. núm. 221.

25 Así, Arroyomolinos y Jaraíz tomaron los que Plasencia pedía a Garganta la Olla, Pasarón y Tarremenga (R.G.S., 1494 Oct. núm. 436).

26 AGS, Cám. Cast. Pueblos, leg. 15

27 AGS, RGS, 1497 Marzo núm. 14 
placentino prohibía a los de señorío entrar y cortar «en comunidad» en los «montes y baldíos" de la ciudad ${ }^{23}$.

Pese a todas estas dificultades, la ciudad fue recuperando algunos términos, y pudo asignar tierras a los Concejos de la Tierra, aunque a juzgar por los testimonios hubo diferencias entre ellos en las concesiones ${ }^{29}$. En todas las peticiones de tierras los Concejos alegaron el peligro de despoblamiento, que fue el mismo argumento dado por los señores para que no se les privara a sus vasallos de pasto común. Y es que los pleitos pusieron de manifiesto que los lugares de señorío gozaban de ulos baldíos y concejiles» como los vecinos de Plasencia y su Tierra. En consecuencia, como fue en el Arañuelo donde preferentemente la ciudad señaló las tierras a sus lugares, el Concejo placentino estableció unas Ordenanzas y otras disposiciones con el fin de proteger el disfrute de todos los vecinos de la Comunidad de esos «baldíos». Así, en las Ordenanzas sobre el quinto en el Arañuelo ${ }^{30}$ se dispuso que todos los lugares de la Tierra, incluidos los de señorío, hicieran vecindades con Plasencia para que sus ganados pudieran pastar allí, pues el ser vecino, requisito que antes se adoptaba, ya no era suficiente a causa de los fraudes que se hacían "y porque la Tierra se había quejado de una Ordenanza dada por el Concejo placentino sin contar con ella ${ }^{32}$. Tampoco estuvo de acuerdo la Tierra con otra Ordenanza del Concejo de la ciudad por la que se ordenó registrar una vez al año el ganado de todos los vecinos de la Comunidad, incluyéndose por tanto a los de señorío, que pastara en los comunes; concejiles y baldíos, so pena de ser quintado ${ }^{3}$. De estas quejas de la Tierra se desprende que se sintió agraviada al ser igualada en el trato con los lugares de señorío, pues, a diferencia de la ciudad, que teóricamente extendía su jurisdicción sobre los pobladores de los señoríos, los lugares de la Tierra placentina no considerat ban a los de señorío como vecinos de ella ${ }^{34}$.

Por otra parte, debemos señalar que las tierras dadas por Plasencia a los lugares de su Tierra en el Arañuelo para dehesas boyales y ejidos no se utilizaron siempre para los bueyes y ganados ni para labrar, sino que se arrendaron para pasto, y con las rentas que se obtenían los Concejos arrendaban otras para bueyes y para labrar más cerca de ellos, porque generalmente las tierras designadas por la ciudad quedaban lejos de los lugares, que estaban la mayoría de las veces rodeados de dehesas adehesadas, como ya dijimos anteriormente. Esta mezcla de dehesas de los señores, que kestaban en medio de los concejiles con malician" ${ }^{3} \mathrm{y}$ dehesas de los Concejos de la Tierra se muestra en la relación de 1498 de las dehesas que Plasencia había dado a favor de los siguientes lugares ${ }^{36}$ : El Toril, cuya dehesa fue acrecentada hasta la de "La Macana», privando de baldíos a Serrejón, y en donde se metió un abrevadero

28 Id., 1496 Dic. núm. 81 y 1498 Oct. núm. 95.

29 Id., 1512 Mayo.

30 A. Cat. Plas., leg. 29 núm. 5.

31 AGS, RGS, 1511 Oct. núm.81

32 Id., 1498 Mayo num. 305.

33 Id., 1509 Julio, 1510 Nov, y 1512 Sept.

34 AGS, Exp. Hac. leg. 358.

33 Idem.

36 AGS, RGS, 1498, Oct. núm. 234. 
llamado «venero del Tinoso"; Saucedilla y Casatejada, con dehesa y ejido hasta El Toril y Serrejón; Casas de Don Millán, con la dehesa de "Picatones» o «del Picatón", que se extendía desde Almaraz a la dehesa del «Espadañal»; Malpartida, en «los Campillos», entre El Toril y el río Tiétar, junto al "Rincón»; Albalá, con una dehesa junto a Serrejón y Almaraz; Serradilla en «los pescadores», junto a los ejidos de la Peraleda y Valdehúncar; Valparaiso, Navalmoral, Torvicoso y Malbincada (todos formaban una Campana o Concejo) recibieron unos ejidos ya que cada lugar tenía dehesa boyal; Aldeanueva de la Vera tuvo la dehesa en el "Collado de la Yegua»; y Plasencia se dio a sí misma una dehesa en "el atalaya» en el lugar de "Atalayuela» y "Malhincadilla» que se habían despoblado, y otra dehesa para propios que rentaba 200.000 mrs., y además adehesó la tierra de la Bazagona, cuya renta se llevaban los regidores de la ciudad.

Por supuesto, los lugares de señorío protestaron de las dehesas dadas a los de la Tierra o de las que se había adjudicado a la ciudad, y tan reiteradas fueron las quejas que los Reyes Católicos ordenaron a Plasencia que cuando señalaran dehesas lo hiciera lo más cerca posible, que fueran boyales y que no se perjudicara a nadie $^{37}$.

\section{2) Influencia en la tenencia y explotación de la tierra}

En las protestas de los lugares de señorío cuando Plasencia señalaba dehesas boyales y ejidos a los de su Tierra se afirmó que, como uen los baldíos no hay para todos», los labradores arrendaban las tierras tomando "quartos» de dehesas" ". Aparece así consolidada la práctica establecida en las Ordenanzas agrarias de don Alvaro de Estúñiga de 1471 para que los campesinos sin tierras labraran un "quarto" de dehesa a cambio de 11 fanegas por yunta de bueyes", renta que los señores y dueños de las tierras elevarían. Ejemplo de ello es la aplicación de las Ordenanzas de don Álvaro para solucionar el conflicto mantenido por los Concejos del Villar y El Oliva con unos vecinos de la ciudad por «la Fresnedilla», sita en El Oliva y que esos Concejos consideraban un antiguo lugar despoblado y baldío de Plasencia: tras un dilatado pleito ${ }^{40}$ se sentenció que los vecinos de esos Concejos pagaran de "terrazgo» 12 fanegas de pan terciado por yunta (dos partes de trigo y una de cebada) de lo que sembraran en una parte de la heredad, deslindándose a Isabel Alfaro y a su marido Rodrigo de Neira, vecinos de la ciudad, «el pozo de los mozos» que el Concejo placentino años más tarde reclamaría como baldío y concejil.

Señores y dueños de las tierras, no obstante, se resistieron a dejar los «quartos» debido a que preferían arrendar toda la dehesa para pasto, sobre todo en el Arañuelo, donde los suelos son poco aptos para la agricultura, a pesar de lo afirmado por los campesinos, que para conseguir el "quarto» decían que el «quarto de pan» valía

37 Id. 1499 Mayo y Agosto núm. 56.

38 AGS, Exp. Hac. leg. 358.

39 Los Reyes Católicos las confirmaron en 1493. (vs. Santos Canalejo, 1981, pp. 205-210).

to AGS, RGS, 1491 Julio núm. 55, 1493 
tanto como la renta de toda la dehesa por lo que el señor o dueño no salía perjudicado. Pero lo cierto es que, cuando se sembraba varios años seguidos en el mismo cuarto, la tierra se agotaba siendo preciso entonces labrarlo de cuatro en cuatro años. Por eso los vecinos de la Tierra solicitaron que hubiera dos «quartos» en la dehesa a fin de que cada uno se labrase de ocho en ocho años ${ }^{41}$.

A veces los señores consiguieron que no se acotaran los "quartos" para labrar ${ }^{42}$, pero cuando lo permitieron fue para reunir las rentas proporcionadas por el arrendamiento de pastos y las del «quarto" junto con los derechos que cobraban a los vecinos que se aprovechaban de esa tierra para labrar, siendo uno de ellos el «terrazgo" que inspirara al fijado por don Álvaro en sus Ordenanzas agrarias. De ahí, que los señores no reconocieran la recuperación de términos por la ciudad y tomaran el pan, en grano y en haces, a los vecinos de los Concejos de la Tierra para obligarles a arrendar tierras en los términos de su señorío. Así, el Señor de Belvís pidió a los de la Campana de Albalá «hebras", "terrazgos", "onzavos" y tres fanegas de cebada al año por par de bueyes, más el terrazgo del pan que recogían en los términos de su lugar de Deleitosa y 15.000 o 16.000 mrs. por las dehesas de «El Rincón» y «El Gato», dehesas que los de la Campaña de Albalá quisieron tener a censo perpetuo pero que no les concedió el Señor de Belvis por ser de gran extensión y valor ${ }^{43}$.

Ahora bien, el "quarto» de la dehesa se destinaba al aprovechamiento agrícola de forma comunal, pues los señores o arrendadores de la dehesa no podían entrar en él desde que comenzaba el barbecho (el 1 de enero) hasta la siega, pero los labradores no pudieron disfrutar de los rastrojos, ni de la montanera, ni de la leña, ni de la madera. Si a esto añadimos que en contra de la costumbre, que permitía a los lugares de la Tierra cortar madera en las dehesas guardando la sexta parte de los árboles y los «propios», los señores no lo consintieron, y que algunos lugares acotaron los rastrojos, cuando también era costumbre que en los concejiles los rastrojos fueran de aprovechamiento comunal, podemos deducir que a fines del XV el aprovechamiento comunal de los términos en Plasencia se encontró limitado, aunque los campesinos pudieron solicitar el cuarto de dehesa y reclamar sus derechos referentes al uso comunal, a diferencia de otros lugares, también de predominio ganadero, como en Arenas, cuyos vecinos tuvieron menos posibilidades pues sólo se podría labrar en Valdeoliva y, para hacer huerto, "cerrado" o labrar deberían tener en cuenta el no perjudicar a la Mesta ${ }^{41}$.

\section{CONCLUSIONES}

El aprovechamiento comunal en propiedades concejiles o particulares tuvo mucha importancia en toda la zona de este estudio. Y fue el de los pastos el más

41 AGS, Cám. Cast., Pueblos, leg. 15.

42 AGS, RGS, 1494 Nov. núm. 204: Los Reyes Católicos permiten a doña María, viuda de don Francisco de Estuñiga, que la dehesa de "San Benito de Roble Nltow no tuviera "quarto" para labrar.

13 AGS, Cám. Cast. personas, leg. 18.

$44 \mathrm{AHN}$, Osuna, leg. 1749 núm. 3 (1 y 2). 
atendido por los vecinos de aquellos Concejos por la importancia de la ganadería en todo ese ámbito.

La propia organización de la Comunidad de Villa y Tierra determinó la protección y explotación de sus términos en beneficio de sus vecinos, si bien a la hora de poner límites al disfrute comunal por esa propia organización resultaron perjudicados los vecinos de los lugares de la Tierra antes que los de la ciudad o villa.

Este aprovechamiento resultó imprescindible no sólo para los campesinos que no tuvieran tierras sino también para los que poseyeran pequeñas propiedades ${ }^{43}$. Además, el acrecentamiento de tierras privadas en detrimento de los «comunes» y "concejiles» hizo todavía más necesario el aprovechamiento «en comunidad», sobre todo cuando la tierra se dedicaba a pastos. Y en Plasencia, los vecinos de las aldeas nacidas en medio de dehesas no contaron más que con tierras concejiles para pasto y labranza.

Sin embargo, no se pudieron evitar los acotamientos por los dueños de las tierras, los señores, e incluso por los Concejos, ya que la costumbre «inmemorial» se quebrantó por la actuación de la oligarquía concejil.

El Campo del Arañuelo se convirtió en un conjunto de dehesas particulares o de propiedad colectiva dedicadas al pasto del ganado trashumante, quedando apenas tierras de «baldíos y comunes» para los vecinos de Plasencia y su Tierra, que ante las malas condiciones del suelo para la agricultura practicaron el cultivo al cuarto e incluso el itinerante.

Con la recuperación de términos, Plasencia pudo compensar con dehesas boyales y ejidos a los lugares de la Tierra que más habían sufrido las usurpaciones de sus heredades y los abusos de los señores, si bien a cambio debieron aceptar que los de señorío gozaran de los baldíos y concejiles de Plasencia, no pudiendo los de la Tierra hacer lo mismo en los términos de los señoríos.

Ahora bien, Plasencia no consiguió las más importantes dehesas del Arañuelo, que habían pertenecido a los Estúñiga y que después rentaron a los titulares de los principales señoríos placentinos, como la de «El Espadañal», "San Benito», "La Macana», «El Gato» o la de «El Rincón», en donde en el siglo XVI aparece la aldea llamada el «Rincón de los Iñigos» ${ }^{46}$.

Los señores en todo momento desearon aumentar sus posesiones tanto para lograr más rentas por los pastos como para que sus vasallos y el resto de los vecinos de la Comunidad pudieran «usarlas» pagando rentas y ciertos derechos. Por eso no reconocieron muchas de las recuperaciones de tierras logradas por la ciudad e incluso mandaron a sus vasallos ocupar alguna dehesa a fin de no perder la percepción de esos tributos y rentas.

Por último, debemos añadir que la orientación ganadera de la dehesa y del monte implicó el cuidado por el arbolado y el pastizal. En Béjar, el Castañar de la Villa era podado y limpiado para que los árboles produjeran abundante fruto ${ }^{47}$, y en Plasencia los barbechos herbáceos se aseguraron con el prolongado descanso de la

45 Cuadrado Iglesias, (1980, p. 89).

46 Sánchez Loro $(1983$, p. 71$)$.

47 A. Mun. Bejar, Carp. 4 núm. 4. 
tierra. Los daños ocasionados al arbolado y al pastizal provinieron la mayoría de las veces por la quema de los rastrojos, pero no por la labor de los campesinos y labradores, pues el aprovechamiento agrícola de la dehesa y monte bajo fue un complemento y no la causa de que el espacio se aclarara de árboles como mucho más tarde sucederá ${ }^{\text {sto }}$.

\author{
Elisa C. de Santos Canalejo
}

García Fernández (1978, pág. 209) y Martín Galindo (1966, p. 164) señalan la importancia de las rozas para mantener el pastizal en las dehesas actuales. 


\section{Bibliografía}

CUADRADO IGLESIAS, M., (1980), Aprovechamiento en común de pastos y letras. Madrid, Minist. de Agricultura, Secretaría General Técnica.

GARCÍA FERNÁNDEZ, J., (1978), "Formas de explotación» en Economía agraria en la Historia de España, Madrid, Alfaguara-Fund. J. March., pp.189-210.

MANGaS Navas, J.M.:' (1981), El régimen comunal agrario de los Concejos de Castilla,, Madrid, Minist. de Agricultura, Secretaría General Técnica.

MARTíN GALINDO, J.L., (1966), «La dehesa extremeña como tipo de explotación agraria" en Estudios Geográficos, n..$^{\circ}$ XXII, pp. 157-226.

SÁNCHEZ LORO, D. (1983), Historias placentinas inéditas. Catalogus Episcoporum Ecclesiae Placentinae, Cáceres, El Brocense, vol. B.

Santos Canalejo, E.C. de, (1981), El siglo XV en Plasencia y su Tierra. Proyección de un pasado y reflejo de una época, Cáceres, El Brocense.

Id., (1986), La historia medieval de Plasencia y su entorno geo-histórico: la Sierra de Béjar y la Sierra de Gredos, Cáceres, El Brocense.

TEJERO ROBLEDO, E., (1973), Mombletrán. Historia de una villa señorial, Madrid, S.M. 